\title{
The Effects of Modafinil Treatment on Neuropsychological and Attentional Bias Performance During 7-Day Inpatient Withdrawal From Methamphetamine Dependence
}

\author{
Robert Hester \\ University of Melbourne, Australia
}

\author{
Nicole Lee \\ Turning Point Alcohol and Drug Centre, Australia
}

\author{
Amy Pennay, Suzi Nielsen, and Jason Ferris \\ Turning Point Alcohol and Drug Centre, Australia; Monash University, Australia
}

\begin{abstract}
The cognitive benefits of modafinil to patients undergoing 7-day inpatient withdrawal from methamphetamine (MA) dependence were examined as part of a double-blind, randomized, placebo-controlled pilot trial. Recent evidence has identified modafinil-related improvements in treatment outcomes for MA-dependent patients; however, the benefits to cognition function, which is critical to treatment success but known to be impaired, has yet to be examined. The first 20 participants recruited to the study were administered either $200 \mathrm{mg}$ of modafinil (once daily) or placebo, and a neuropsychological test battery (including an MA version of the emotional Stroop task) at admission $(n=17)$ and discharge $(n=14)$. Follow-up interviews were conducted at 1 -month postdischarge $(n=13)$. After participant withdrawals ( 3 in each group), treatment was associated with a significant improvement in immediate verbal memory recall and nonsignificant trend toward improvement on executive function and delayed memory tasks. No benefit was seen for measures of verbal learning, visual memory, processing speed, or verbal fluency. All participants showed a significant attentional bias for MA-related stimuli on the emotional Stroop task. The magnitude of bias predicted both retention in treatment and relapse potential at follow-up but was not significantly ameliorated by modafinil treatment. While nonsignificant, the effect sizes of modafinil-related improvements in executive function and memory were consistent with those found in more robustly powered studies of cognitive benefits in attention-deficit/hyperactivity disorder and schizophrenia, supporting the need for further research.
\end{abstract}

Keywords: methamphetamine, neuropsychological performance, emotional Stroop, attentional bias, modafinil

Use of the stimulant drug methamphetamine (MA) in Australia is more than twice that of other developed countries (United Nations Office on Drugs \& Crime, 2007), with over $6 \%$ of the population having used MA in their lifetime. The most recent survey of MA use indicates Australia has 81,000 weekly users ( $0.5 \%$ of population) and 178,000 monthly users (1.0\%; AIHW, 2008), with $56 \%$ of "regular" users meeting the criteria for MA dependence (McKetin, Kell, \& McLaren, 2006; McKetin, McLaren, Kelly, Hall, \& Hickman, 2005; McKetin, McLaren, Lubman, \& Hides,
Robert Hester, Department of Psychological Sciences, University of Melbourne, Parkville, Victoria, Australia; Nicole Lee, Turning Point Alcohol and Drug Centre, Fitzroy, Victoria, Australia; Amy Pennay, Suzi Nielsen, and Jason Ferris, Turning Point Alcohol and Drug Centre, Fitzroy, Victoria, Australia; Eastern Health Clinical School, Monash University, Clayton, Victoria, Australia.

Nicole Lee is now at the National Centre for Education and Training on Addictions (NCETA), Flinders University, Adelaide, Australia.

This research was supported by the Illicit Drugs Section, Drugs Strategy Branch, Australian Government Department of Health and Ageing and National Health and Medical Research Council Fellowship (519730) (to R.H.). The Department of Health and Ageing had no further role in study design; in the collection, analysis and interpretation of data; in the writing of the report; or in the decision to submit the paper for publication R.H. developed the cognitive tasks and neuropsychological battery, analyzed and interpreted the data, and wrote the article. N.L. developed the measures and design for the entire randomized clinical trial, A.P. recruited participants and administered the cognitive tests. J.F. provided statistical advice. S.N. dispensed the trial medication. All authors contributed to the drafts of the article. All authors declare that they have no conflicts of interest. The assistance of clinical staff at both sites are gratefully acknowledged. Our trial is registered with the Australian New Zealand Clinical Trials Registry - number is ACTRN12606000272594.

Correspondence concerning this article should be addressed to Robert Hester, Department of Psychological Sciences, University of Melbourne, Parkville, Victoria 3010, Australia.E-mail: hesterr@ unimelb.edu.au 
2006). Effective treatment for MA dependence is critical to circumventing the individual and community harms associated with its use; however, recent statistics indicate low levels of treatment seeking and poor treatment compliance among this group (AIHW, 2007). One factor contributing to this paradox is the absence of a specific pharmacotherapy for MA withdrawal (Lee, Pennay, Harney, Kenny, \& Johns, 2007; McLaughlin, McKenna, \& Leslie, 2000).

Withdrawal from MA is reported to result in a low level of physical symptomatology that features agitation, insomnia, and fatigue, but includes a more severe level of psychological symptoms, including depression, anxiety, anhedonia, and cognitive dysfunction (McGregor et al., 2005; McGregor et al., 2008). Given the high level of treatment dropout, previous pharmacotherapy has focused on mood and insomnia with medications such as antidepressants, with mixed success (Shoptaw, Kao, Heinzerlin, \& Ling, 2009).

Modafinil is a nonamphetamine psychostimulant that was initially approved for the treatment of narcolepsy but was subsequently shown to have success in clinical trials treating cocaine dependence (Anderson et al., 2009; Dackis, Kampman, Lynch, Pettinati, \& O'Brien, 2005; Dackis et al., 2003). The pharmacological mechanism(s) of modafinil's action has yet to be clearly determined (see Minzenberg \& Carter, 2007, for a review), with effects on multiple neurotransmitter systems including catecholamine, serotonin, glutamate, GABA, orexin, and histamine systems. The cognitive enhancing effects of modafinil have been associated with its action on the binding (or blocking) of dopamine and norepinephrine transporters (Hermant, Rambert, \& Duteil, 1991; Madras et al., 2006), and resulting in increased extracellular dopamine in cortical regions critical to cognition (Volkow et al., 2009).

In healthy adults, modafinil has been associated with significant improvements in working memory and executive function (Turner et al., 2003), while sleep-deprived participants have shown more general benefits to attention, psychomotor speed, memory, and executive function (Gill, Haerich, Westcott, Godenick, \& Tucker, 2006; Randall, Fleck, Shneerson, \& File, 2004; Westcott, 2005). More recently, modafinil has been used to treat cognitive dysfunction in conditions such as attention-deficit/hyperactivity disorder (ADHD; Greenhill et al., 2006; Kahbazi et al., 2009), schizophrenia (Hunter, Ganesan, Wilkinson, \& Spence, 2006; Morein-Zamir, Turner, \& Sahakian, 2007; Turner, Clark, Pomarol-Clotet, et al., 2004) and where fatigue is a side effect of treating the principal condition (Minzenberg $\&$ Carter, 2007). We are not aware of any published research examining the effect of modafinil on drug-dependent groups, and the clinical trials of modafinil for cocaine and MA dependence (De La Garza, Zorick, London, \& Newton Heinzerling (2010); McElhiney et al., 2009; McGregor et al., 2008; Shearer et al., 2009) have not examined cognitive performance.

Recent randomized trials of modafinil to treat MA-dependent users (De La Garza et al., 2010; Heinzerling et al., 2010; McElhiney et al., 2009; McGaugh et al., 2009; McGregor et al., 2008; Shearer et al., 2009) have shown the drug to be well tolerated with limited side effects and minimal adverse events (particularly at $200 \mathrm{mg}$ ), but none have examined the benefits to cognition.

Current research indicates that cognitive processes are fundamental for the ability to inhibit the immediate pursuit of pleasurable stimuli, and for the development of adaptive patterns of behavior - both key factors in drug dependence (Kalivas \& Volkow, 2005). Chronic MA users tested during a nonintoxicated state consistently display cognitive deficits in memory, attention and psychomotor speed, as well as marked deficits on clinical neuropsychological and experimental measures of executive control (Salo, Nordahl, Moore, et al., 2002; Simon et al., 2002). One aspect of executive dysfunction that has become of particular interest in drug dependence research has been the attentional bias, or difficulty controlling attention away from, substance-related stimuli (Field \& Cox, 2008). Behavioral studies have shown that processing a nonsalient stimulus in the presence of more salient stimuli represents a significant difficulty for those dependent on drugs such as alcohol (Cox, Brown, \& Rowlands, 2003), and heroin (Franken, Stam, Hendriks, \& van den Brink, 2003), nicotine (Bradley, Field, Mogg, \& De Houwer, 2004; Field, Mogg, \& Bradley, 2004) and cocaine (Copersino et al., 2004; Franken, Kroon, \& Hendriks, 2000; Hester, Dixon, \& Garavan, 2006), with greater bias predicting poorer outcomes during drug-treatment programs (Carpenter, Schreiber, Church, \& McDowell, 2005; Cox, Hogan, Kristian, \& Race, 2002). The attentional bias is argued to reflect the salience of drug-related stimuli. As salience directs attention relatively automatically, a greater level of cognitive control must be imposed to ignore the salient stimulus and instead attend to a less salient stimulus (Field \& Cox, 2008). Recent work has also demonstrated that psychological intervention with alcohol users (Schoenmakers et al., 2010) and pharmacological intervention with stimulant users (Ersche et al., 2010) was associated with a reduction in attentional bias that accompanied improved treatment outcomes. This work highlights the potential usefulness of attentional bias as a cognitive index of relapse potential and treatment effectiveness, though to date attentional bias tasks have not been adapted for use with MA using populations.

Administration of cognitive tests during withdrawal indicate a further acute deterioration in cognition, with MA users tested 7 days after their last use showing marked cognitive deficits on tests of psychomotor speed, attention, memory and executive control (Simon et al., 2004). These results highlight the unfortunate coincidence that during withdrawal, when the requirement for control over one's behavior faces the greatest challenge from both physical and emotional urges to resume drug use, cognitive performance, and executive control in particular, are most impaired. Treatment to assist with cognitive dysfunction may directly assist with these difficulties, as well as providing indirect benefits to treatment such as greater cognitive capacity for engagement in cognitive-behavioral therapy, the principal treatment for MA dependence.

The aim of the present study was to examine the cognitive benefits of modafinil to patients undergoing 7-days of 
inpatient withdrawal from MA as part of a pilot, doubleblind, randomized, placebo-controlled trial examining a range of treatment outcome measures (reported elsewhere).

\section{Method}

\section{Participants}

Twenty participants $(6$ women, mean age $=34.3$, range $=21-48)$ were recruited from two drug withdrawal treatment sites via advertising and word of mouth. Both treatment sites are short-term (5- to 7-day stay) residential withdrawal units located in metropolitan Melbourne. Patients who sought inpatient treatment for MA dependence were offered the opportunity to participate in the trial. Inclusion criteria for the study required patients to be 18 years and over, met the Diagnostic and Statistical Manual for Mental Disorders, Fourth Edition (DSM-IV) diagnosis of current MA dependence but the absence of dependence on any other drug except nicotine and marijuana, and had used MA in the past 48 hours (confirmed via saliva test, iScreen OFD, Instant Technologies, Norfolk, VA). Exclusion criteria included not suffering from active psychosis or current major depression, current or past history of conditions with the potential to impair cognition (e.g., stroke, traumatic brain injury, ADHD, epilepsy), returning positive urine screen samples for any drug other than MA, nicotine, or marijuana or presenting with any contraindications for modafinil treatment (e.g., previous adverse reaction, pregnancy, breastfeeding).

Participants were fully informed of the nature of the research and provided written consent for their involvement in accordance with the requirements of the Health Human Research Ethics Committee of Western Health. Participants reported other drug use in the month prior to interview, with the self-reported use detailed in Table 1 . Not shown in Table 1 are the frequencies of other illicit drug use. At screening, by self-report about the past 30 days, overall frequency of cocaine use was $7 \%$, heroin $14 \%$, ecstasy $35 \%$, benzodiazepines $71 \%$, alcohol $64 \%$, and cannabis $64 \%$. The groups were not significantly different on these frequency rates.

\section{Treatment}

During the 7 days of inpatient treatment, participants took a $200 \mathrm{mg}$ tablet of modafinil, or the matched placebo, once daily upon awakening, from the 1 st to the 5th day. On the 6th and 7th days participants in the modafinil treatment group received a $100 \mathrm{mg}$ tablet, to titrate the dose prior to discharge. Modafinil and placebo was purchased, prepared, randomized and dispensed by the study pharmacist. All investigators, doctors, nursing staff, researchers and participants were blind to the medication assignment. Randomizations were created in blocks of four using a computerized randomization program. All participants received general support as usual from the nursing and medical staff and upon completion of the trial were offered standard referral for ongoing support and treatment. Following inpatient discharge, participants did not receive either modafinil or placebo medication.

\section{Assessment Measures}

Questionnaires. A battery of questionnaires, the results of which are presented elsewhere, was administered at treatment entry and discharge. They included a range of demographic, drug use history and mental health questions as well as daily clinical measures addressing withdrawal and physiological changes.

Neuropsychological tests. A battery of clinical neuropsychological measures were administered to participants on the day of admission (prior to receiving modafinil or placebo treatment) and on the day of discharge. The measures were chosen to sample performance from a range of cognitive domains previously shown to be impaired in MA dependent participants, including (i) verbal and visual memory: Rey Auditory Verbal Learning test (RAVLT), Rey Complex Figure test (RCFT), (ii) working memory: Digit Span test, (iii) psychomotor speed: Digit-Symbol Substitution test, and (iv) executive function: Controlled Oral Word Association test (COWAT), Trail Making test, Stroop Test. Alternate forms were used for all measures and counterbalanced across participants. The baseline assessment also included an administration of the National Adult Reading Test (version 2) to assess premorbid verbal IQ.

MA stroop task. The cocaine-related emotional Stroop task described by Hester, Dixon, \& Garavan, 2006) was adapted for the current study. The task presented 3 blocks of 90 trials, interspersed by short rest breaks. The stimuli in the MA-related emotional Stroop included words from each of the following categories: MA-related (e.g., meth, ice) and neutral words (e.g., box, telephone), incongruent (classic Stroop) color words, and congruent color words. The MArelated words, "meth," "ice," "wizz," "powder," "speed," and "louey" were derived from the six most frequently nominated words from a questionnaire completed by 15 active MA-users seen at Turning Point Alcohol and Drug Centre. Each task block presented 72 congruent color trials, pseudorandomly interspersed with 18 "critical" trials (six words from each of the three other word categories). Training prior to the main task familiarized participants with responding to the color of the word stimuli via the keypad of a standard keyboard, with colored stickers indicating the four different response buttons. A single trial presented the word stimulus on a black background where it remained until the participant responded, following which a $250-\mathrm{ms}$ blank screen and a 500-ms fixation cross would be presented prior to the next word stimulus.

\section{Results}

\section{Treatment Retention and Compliance}

Of the 20 participants recruited to the study, two participants were unable to complete the neuropsychological tests because of illiteracy, and one participant was later found to be ineligible and their data removed. All 17 remaining participants completed the baseline neuropsychological session, three participants did not complete the discharge session, and of these 14 participants one could not be interviewed at the 1-month follow-up session (two participants tested at baseline but not 
Table 1

Mean and SEM for Placebo and Modafinil Treatment Groups on: (A) Demographic and Drug Use History, (B) Performance on Neuropsychological Measures at Baseline and Discharge Sessions

\begin{tabular}{|c|c|c|c|c|c|c|c|c|}
\hline & & \multicolumn{3}{|c|}{ Modafinil } & & \multicolumn{3}{|c|}{ Placebo } \\
\hline & & $M$ & & SEM & & $M$ & & SEM \\
\hline \multicolumn{9}{|l|}{ (A) Demographic Variables } \\
\hline Age & & 32.3 & & 2.5 & & 35.3 & & 2.9 \\
\hline Years of education & & 11.6 & & 0.4 & & 12.3 & & 0.6 \\
\hline Verbal IQ (NART) & & 99.3 & & 4.6 & & 102.3 & & 4.2 \\
\hline Leeds Dependence Scale & & 22.1 & & 1.2 & & 23.6 & & 1.5 \\
\hline Brief Symptom Inventory & & 112.3 & & 13.3 & & 85.7 & & 11.4 \\
\hline \multicolumn{9}{|l|}{ Methamphetamine } \\
\hline Days of use in last month & & 15.3 & & 1.7 & & 18.0 & & 2.4 \\
\hline No. of uses in last month & & 89.7 & & 25.3 & & 65.0 & & 20.5 \\
\hline Lifetime duration & & 10.5 & & 3.2 & & 5.0 & & 1.4 \\
\hline Benzodiazepines & & 55.4 & & 32.3 & & 28.5 & & 23.4 \\
\hline Alcohol & & 10.3 & & 4.8 & & 12.8 & & 6.5 \\
\hline Cannabis & & 221.4 & & 98.4 & & 43.1 & & 28.1 \\
\hline Ecstasy & & 3.2 & & 1.5 & & 0.1 & & 0.1 \\
\hline \multirow[t]{3}{*}{ Opiates } & & 3.3 & & 2.8 & & 0.0 & & 0.0 \\
\hline & \multicolumn{2}{|c|}{ Baseline } & \multicolumn{2}{|c|}{ Discharge } & \multicolumn{2}{|c|}{ Baseline } & \multicolumn{2}{|c|}{ Discharge } \\
\hline & $M$ & SEM & $M$ & SEM & $M$ & SEM & $M$ & $M$ \\
\hline \multicolumn{9}{|l|}{ (B) Neuropsychological measures } \\
\hline RAVLT Delayed & 7.9 & 1.6 & 8.6 & 1.2 & 7.0 & 1.6 & 7.2 & 1.1 \\
\hline RAVLT Recognition & 45.0 & 1.6 & 44.1 & 1.4 & 44.6 & 1.6 & 45.0 & 1.4 \\
\hline RAVLT Recall B & 3.7 & 0.4 & 5.9 & 0.5 & 4.4 & 0.4 & 4.6 & 0.5 \\
\hline RAVLT Recall A & 9.3 & 1.4 & 9.6 & 1.0 & 8.3 & 1.4 & 8.9 & 1.0 \\
\hline RCFT Copy & 32.2 & 1.4 & 31.9 & 0.8 & 28.0 & 1.4 & 30.6 & 0.8 \\
\hline RCFT Delay & 18.0 & 2.5 & 19.6 & 1.8 & 16.1 & 2.5 & 16.4 & 1.8 \\
\hline Digits Forward & 11.0 & 0.9 & 11.0 & 0.9 & 11.6 & 0.9 & 11.0 & 0.9 \\
\hline Digits Backward & 7.1 & 0.7 & 7.3 & 1.1 & 6.4 & 0.7 & 6.7 & 1.0 \\
\hline Digit Symbol & 55.7 & 3.5 & 58.6 & 3.7 & 53.9 & 3.5 & 54.7 & 3.7 \\
\hline COWAT Total & 44.9 & 4.8 & 52.6 & 6.7 & 46.3 & 4.8 & 52.9 & 6.7 \\
\hline COWAT Animals & 23.7 & 1.9 & 26.0 & 2.3 & 20.6 & 1.9 & 22.9 & 2.3 \\
\hline Trails A & 28.9 & 2.8 & 27.7 & 2.3 & 32.1 & 2.8 & 23.3 & 2.3 \\
\hline Trails B & 64.7 & 6.7 & 58.8 & 9.1 & 56.9 & 6.7 & 66.6 & 9.1 \\
\hline Trails B-A & 35.9 & 6.0 & 31.1 & 8.6 & 24.7 & 6.0 & 43.2 & 8.6 \\
\hline \multicolumn{9}{|l|}{ Stroop Task } \\
\hline Color & 725.9 & 52.4 & 681.9 & 54.9 & 740.0 & 62.0 & 713.1 & 65.0 \\
\hline Methamphetamine & 833.8 & 54.5 & 764.4 & 48.6 & 833.5 & 64.5 & 780.0 & 57.5 \\
\hline Neutral & 776.8 & 45.4 & 698.3 & 39.6 & 775.1 & 53.8 & 751.5 & 46.8 \\
\hline Incongruent & 934.6 & 71.3 & 882.2 & 67.3 & 1011.3 & 84.4 & 966.5 & 79.7 \\
\hline
\end{tabular}

Note. $\quad$ NART $=$ National Adult Reading Test; RAVLT $=$ Rey Auditory Verbal Learning Test; RCFT = Rey Complex Figure Test; COWAT $=$ Controlled Oral Word Association Test. The measures of drug use in Part (A), unless otherwise stated, represent the self-reported mean number of uses in the last month. The groups did not differ significantly on any of these baseline measures. Significant improvement in neuropsychological performance across sessions as a result of modafinil is highlighted with bolding of text in Part (B).

discharge were also interviewed at follow-up). No adverse events were reported by the sample taking modafinil and participants reported tolerating the medication well.

Follow-up interviews conducted 1 month after discharge indicated 7 of the 13 (3 of 6 placebo, 4 of 7 modafinil) available participants reported using MA in the period following inpatient discharge. Participants also provided a saliva drug test at the follow-up interview, which provided confirmation of MA use during the 48-hr prior. No participant who reported abstaining from MA had a positive saliva test, however 3 participants who self-reported MA use did not test positive due to the MA use being outside the test window.

\section{Neuropsychological Tests}

To examine the effect of experimental treatment of neuropsychological test performance, repeated measures analysis of variance (ANOVA) with session (baseline, discharge) as the within-subjects factor and treatment group (Modafinil, Placebo) as the between-subjects factor, was used. Only one measure from the RAVLT memory test, RAVLT Recall B, displayed a significant interaction effect between session and group, $F(1,10)=3.72, p<.05)$, with performance improving from baseline to discharge for the modafinil group, but not controls. All other test outcomes indicated neither a main effect of session nor an interaction between session and group. The effect sizes (partial eta squared) for interaction effects was typically below $\eta^{2}=.10$, and only three measures: RAVLT Recall B $\left(\eta^{2}=.30\right)$, Trails B-A $\left(\eta^{2}=.17\right)$, and Trails B $\left(\eta^{2}=\right.$ .11) were above that threshold.

In general, performance on the battery indicated improvement across time for both groups. The data on mean percentage change from baseline to discharge is presented in Figure 1. 


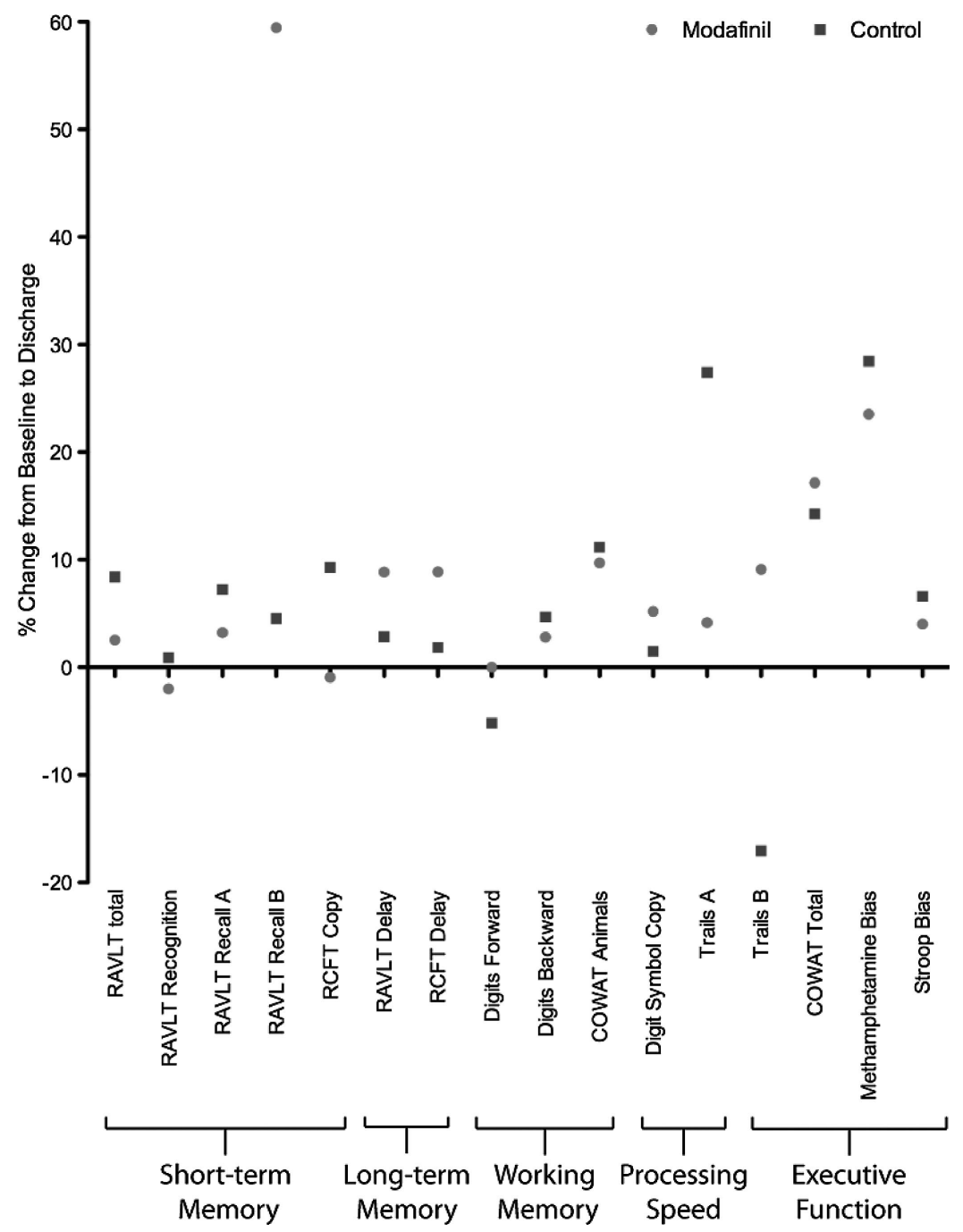

Figure 1. The mean percentage change in cognitive performance from the baseline to discharge session is presented for Modafinil and Placebo treatment groups. Percentage change measures from the Trail Making Test and Emotional Stroop task, where decreases in response time indicate improvement, have been inverted for consistency across measures.

\section{Word Emotional Stroop Task}

Accuracy performance for both users and controls was close to ceiling (over 96\%) for all categories except Stroop trials, which was around $90 \%$ (modafinil $=89 \%$, placebo $=$ $92 \%)$. Accuracy rates did not indicate any significant main effects of group, and the interaction between these factors did not reach significance for MA-related words, $F(1$, 10) $\left.=2.30, p=.15, \eta^{2}=.19\right)$.

The mean reaction time (RT) and standard error scores for correct responses from both the control and modafinil groups are presented in Table 1 . The RTs were analyzed using a $2 \times 2 \times 4$ repeated-measures ANOVA, with group (modafinil, placebo) the between-participants variable and stimulus type (MA, neutral, congruent, incongruent) and session (baseline, discharge) the within-participant variables. There were significant main effect for stimulus type
$F(3,30)=41.9, p<.01$, and session, $F(1,10)=9.31, p=$ .01 , but not group, $F(1,10)=0.19, p=.66$. The mean RT data indicate response times for the discharge session were significantly faster than during baseline, and response times for all stimulus type conditions were significantly different ( $p<.01$ for all post hoc comparisons), with congruent, neutral, MA and incongruent the order from fastest to slowest. The interaction between group and stimulus type was nonsignificant, $F(1,10)=0.55, p=.47$.

To examine executive dyscontrol for MA-related stimuli an attentional bias score was calculated by subtracting the response time to neutral words from MA-related words Participants showed a significant attentional bias for MArelated words at both baseline: $57 \mathrm{~ms}(S D=68)$, $t(11)=2.90, p=.01$, and discharge: $50 \mathrm{~ms}(S D=44)$, $t(11)=3.95, p<.01$. A repeated measures 2 session $\times 2$ 
Group ANOVA indicated neither a main effect of session, $F(1,10)=0.54, p=.48$, group $F(1,10)=0.57, p=.57$, nor an interaction between session and group, $F(1$, 10) $=1.91, p=.20, \eta^{2}=.19$. The same pattern of results was demonstrated for Incongruent "Stroop" trials, whereby both sessions indicated a significant difficulty responding to the words (greater than neutral), but no main effect of session, group, or interaction.

A Pearson correlation coefficient analysis examined the relationship between bias scores and behavioral measures of treatment retention and relapse. Relapse is defined as selfreported use of MA following inpatient discharge. The baseline MA-bias score significantly correlated with the number of days retained in treatment $(n=15, r=-.60$, $p=.019)$, but did not reach significance for self-reported relapse at follow-up ( $n=13, r=-.42, p=.17)$. The relationship between individual differences in the discharge MA-bias score and the number of self-reported MA uses during the period between discharge and follow-up $(n=13$, $r=.54, p=.07$ ), also failed to reach significance. The direction of these relationships indicate that greater bias for MA-related words was related to increased risk of early discharge from treatment, relapse following treatment and MA usage postrelapse.

The Incongruent Stroop bias score was not significantly related to any of the aforementioned measures of MA-use behavior.

\section{Discussion}

The results of this pilot randomized controlled trial indicate that a 7-day inpatient withdrawal treatment administering modafinil to dependent MA users improved performance on a measure of immediate verbal memory (RAVLT List B recall). Measures of delayed memory recall (RAVLT delayed recall, RCFT delayed recall) and executive function (Trails Making Test Part B, Stroop bias and accuracy scores) all demonstrated a nonsignificant trend toward improved performance during modafinil treatment; however, the effect sizes were in the small category $\left(\eta^{2}=.10-.20\right)$.

The neuropsychological performance of the current sample is also consistent with previous evidence of cognitive deficits observed in active and abstinent MA users (for reviews, see Meredith, Jaffe, \& Ang-Lee, 2005; Nordahl, Salo, \& Leamon, 2003; Scott et al., 2007), particularly in the domains of memory and learning (Gonzalez, 2004; Kalechstein, Newton, \& Green, 2003), psychomotor speed (Volkow, Chang, Wang, Fowler, et al., 2001), and executive function (Cherner et al., 2010; Monterosso, Aron, Cordova, $\mathrm{Xu}$, \& London, 2005; Salo, Nordahl, Possin, Leamon, M., \& Gibson, 2002; Salo et al., 2005; Simon et al., 2004; Simon, Dean, Cordova, Monterosso, \& London, 2010). With prolonged abstinence (of at least 12 months), there is some recovery of function (Iudicello et al., 2010); however, over shorter periods of abstinence neuropsychological performance has been shown to decline further (Mccann et al., 2007; Simon et al., 2004; Simon et al., 2010). MA-related cognitive deficits have also been linked to a variety of cortical differences between MA users and matched con- trols, including fronto-cortical dysfunction (London et al., 2005; Monterosso et al., 2007; Paulus, Tapert, \& Schuckit, 2005; Thompson, 2004), dopaminergic transporter levels (Mccann et al., 2007; Volkow, Chang, Wang, Fowler, Franceschi, et al., 2001; Volkow, Chang, Wang, Fowler, et al., 2001), and striatal dopamine receptor levels (Lee et al., 2009).

The small sample size in the current pilot study did not provide the statistical power to detect small effects; however, it is of note that previous studies with larger samples have detected clinically significant benefits from modafinil treatment to cognitive performance in patients with ADHD (Turner, Clark, Pomarol-Clotet, et al., 2004b)-Digit Span Forwards $\eta^{2}=.28$, delayed pattern recognition memory $\eta^{2}=.24$, Stop Signal RT $\eta^{2}=.26$ ) and Schizophrenia (e.g., Turner, Clark, Dowson, Robbins, \& Sahakian, 2004): Digit Span Forwards $\eta^{2}=.19$, Digit Span Backwards $\eta^{2}=.13$, Tower of London extra dimensional shifts $\eta^{2}=.26$ ).

These previous results highlight the potential to identify significant improvements in performance as a result of modafinil treatment, given the magnitude of effect sizes we have detected in the pilot study, with additional data collection. While larger studies of modafinil treatment for MA dependence have been conducted (De La Garza et al., 2010; Heinzerling et al., 2010; McElhiney et al., 2009; McGregor et al., 2008; Shearer et al., 2009), none have to date examined the influence on cognitive function. While our results are preliminary, it is hoped that the trend of results from this pilot study prompt larger scale studies to include cognitive testing. Recent work by Ersche and colleagues (2010) has demonstrated the potential to improve cognitive performance (specifically reducing attentional bias for drug-related stimuli), in stimulant dependent patients using pharmacological intervention. Given the relationship between cognitive control, attentional bias and abstinence in stimulant users (Carpenter et al., 2005; Copersino et al., 2004; Streeter et al., 2008), evidence for the efficacy of such medications in improving cognition would be of great value.

The procedure of tailoring the modafinil dose from 200 $\mathrm{mg}$ to $100 \mathrm{mg}$ on the two days prior to the discharge testing session may also have diminished the benefit derived from modafinil to cognitive performance. Animal and blinded controlled trials in healthy and nonpsychiatric populations (e.g., narcolepsy) have demonstrated dose-related effects on cognition when moving from $100 \mathrm{mg}$ to $200 \mathrm{mg}$ (Minzenberg \& Carter, 2007).

Our participants' drug-use histories showed that, at baseline, the modafinil group had a greater duration (10 vs. 5 years) and recent frequency of MA use, as well as nonsignificantly higher levels of recent benzodiazepine, cannabis, ecstasy and alcohol use. These factors might indicate a higher severity of illness in the modafinil treated group, which has the potential to obscure any medication effect and bias outcomes toward a null result.

The finding of a significant attentional bias for MArelated stimuli adds to a growing literature demonstrating similar drug-specific effects in almost all drug dependent groups (Field \& Cox, 2008). A strong relationship between 
baseline levels of MA-related attentional bias and treatment retention, and discharge levels of bias and relapse rates is consistent with similar findings in heroin (Marissen et al., 2006), nicotine (Waters et al., 2003) and alcohol (Cox et al., 2002) samples. These findings support the association between attentional bias and drug craving and highlight the potential of using this cognitive task as an objective index to track changes in craving and in turn risk for relapse (Field, Munafo, \& Franken, 2009).

\section{References}

Australian Institute of Health and Welfare. (2007). Alcohol and other drug treatment services in Australia 2005-6: Report on the National Minimum Data Set. Drug Treatment Series No 7. Canberra: AIHW.

Australian Institute of Health and Welfare. National drug strategy household survey 2007: First results. Drug statistics series number 20. Cat. no. PHE 98. Canberra: AIHW 2008.

Anderson, A. L., Reid, M. S., Li, S. H., Holmes, T., Shemanski, L., Slee, A., Smith, E. V., et al. (2009). Modafinil for the treatment of cocaine dependence. Drug and Alcohol Dependence, 104, 133-139.

Bradley, B., Field, M., Mogg, K., \& De Houwer, J. (2004). Attentional and evaluative biases for smoking cues in nicotine dependence: Component processes of biases in visual orienting. Behavioural Pharmacology, 15, 29-36.

Carpenter, K. M., Schreiber, E., Church, S., \& McDowell, D. (2005). Drug Stroop performance: Relationships with primary substance of use and treatment outcome in a drug-dependent outpatient sample. Addictive Behaviors, 31, 174-181.

Cherner, M., Suarez, P., Casey, C., Deiss, R., Letendre, S., Marcotte, T., Vaida, F., et al. (2010). Methamphetamine use parameters do not predict neuropsychological impairment in currently abstinent dependent adults. Drug and Alcohol Dependence, 106, $154-163$

Copersino, M. L., Serper, M. R., Vadhan, N., Goldberg, B. R., Richarme, D., Chou, J. C., Stitzer, M., et al. (2004). Cocaine craving and attentional bias in cocaine-dependent schizophrenic patients. Psychiatry Research, 128, 209-218.

Cox, W. M., Brown, M. A., \& Rowlands, L. J. (2003). The effects of alcohol cue exposure on non-dependent drinkers' attentional bias for alcohol-related stimuli. Alcohol and Alcoholism, 38, 45-49.

Cox, W. M., Hogan, L. M., Kristian, M. R., \& Race, J. H. (2002). Alcohol attentional bias as a predictor of alcohol abusers' treatment outcome. Drug and Alcohol Dependence, 68, 237-243.

Dackis, C. A., Kampman, K. M., Lynch, K. G., Pettinati, H. M., \& O'Brien, C. P. (2005). A double-blind, placebo-controlled trial of modafinil for cocaine dependence. Neuropsychopharmacology, 30, 205-211.

Dackis, C. A., Lynch, K. G., Yu, E., Samaha, F. F., Kampman, K. M., Cornish, J. W., Rowan, A., et al. (2003). Modafinil and cocaine: A double-blind, placebo-controlled drug interaction study. Drug and Alcohol Dependence, 70, 29-37.

De La Garza, R., 2nd, Zorick, T., London, E. D., \& Newton, T. F. (2010). Evaluation of modafinil effects on cardiovascular, subjective, and reinforcing effects of methamphetamine in methamphetamine-dependent volunteers. Drug and Alcohol Dependence, 106, 173-180.

Ersche, K. D., Bullmore, E. T., Craig, K. J., Shabbir, S. S., Abbott, S., Müller, U., Ooi, C., et al. (2010). Influence of compulsivity of drug abuse on dopaminergic modulation of attentional bias in stimulant dependence. Archives of General Psychiatry, 67, 632644.

Field, M., \& Cox, W. M. (2008). Attentional bias in addictive behaviors: A review of its development, causes, and consequences. Drug and Alcohol Dependence, 97, 1-20.

Field, M., Mogg, K., \& Bradley, B. P. (2004). Eye movements to smoking-related cues: Effects of nicotine deprivation. Psychopharmacology (Berlin), 173, 116-123.

Field, M., Munafo, M. R., \& Franken, I. H. (2009). A metaanalytic investigation of the relationship between attentional bias and subjective craving in substance abuse. Psychological Bulletin, 135, 589-607.

Franken, I. H., Kroon, L. Y., \& Hendriks, V. M. (2000). Influence of individual differences in craving and obsessive cocaine thoughts on attentional processes in cocaine abuse patients. Addictive Behaviours, 25, 99-102.

Franken, I. H., Stam, C. J., Hendriks, V. M., \& van den Brink, W. (2003). Neurophysiological evidence for abnormal cognitive processing of drug cues in heroin dependence. Psychopharmacology (Berlin), 170, 205-212.

Gill, M., Haerich, P., Westcott, K., Godenick, K. L., \& Tucker, J. A. (2006). Cognitive performance following modafinil versus placebo in sleep-deprived emergency physicians: A doubleblind randomized crossover study. Academic Emergency Medicine, 13, 158-165.

Gonzalez, R. (2004). Neurocognitive performance of methamphetamine users discordant for history of marijuana exposure. Drug and Alcohol Dependence, 76, 181-190.

Greenhill, L. L., Biederman, J., Boellner, S. W., Rugino, T. A., Sangal, R. B., Earl, C. Q., Jiang, J. G., et al. (2006). A randomized, double-blind, placebo-controlled study of modafinil filmcoated tablets in children and adolescents with attention-deficit/ hyperactivity disorder. Journal of the American Academy of Child and Adolescent Psychiatry, 45, 503-511.

Heinzerling, K. G., Swanson, A. N., Kim, S., Cederblom, L., Moe, A., Ling, W., \& Shoptaw, S. (2010). Randomized, double-blind, placebo-controlled trial of modafinil for the treatment of methamphetamine dependence. Drug and Alcohol Dependence, 109, $20-29$.

Hermant, J. F., Rambert, F. A., \& Duteil, J. (1991). Awakening properties of modafinil: Effect on nocturnal activity in monkeys (Macaca mulatta) after acute and repeated administration. Psychopharmacology (Berlin), 103, 28-32.

Hester, R., Dixon, V., \& Garavan, H. (2006a). A consistent attentional bias for drug-related material in active cocaine users across word and picture versions of the emotional Stroop task. Drug and Alcohol Dependence, 81, 251-257.

Hunter, M. D., Ganesan, V., Wilkinson, I. D., \& Spence, S. A. (2006). Impact of modafinil on prefrontal executive function in schizophrenia. American Journal of Psychiatry, 163, 2184 2186.

Iudicello, J. E., Woods, S. P., Vigil, O., Cobb Scott, J., Cherner, M., Heaton, R. K., Hampton Atkinson, J., et al. (2010). Longer term improvement in neurocognitive functioning and affective distress among methamphetamine users who achieve stable abstinence. Journal of Clinical \& Experimental Neuropsychology, 32, 704-718.

Kahbazi, M., Ghoreishi, A., Rahiminejad, F., Mohammadi, M. R., Kamalipour, A., \& Akhondzadeh, S. (2009). A randomized, double-blind and placebo-controlled trial of modafinil in children and adolescents with attention deficit and hyperactivity disorder. Psychiatry Research, 168, 234-237. 
Kalechstein, A. D., Newton, T. F., \& Green, M. (2003). Methamphetamine dependence is associated with neurocognitive impairment in the initial phases of abstinence. Journal of Neuropsychiatry and Clinical Neurosciences, 15, 215-220.

Kalivas, P. W., \& Volkow, N. D. (2005). The neural basis of addiction: A pathology of motivation and choice. American Journal of Psychiatry, 162, 1403-1413.

Lee, B., London, E. D., Poldrack, R. A., Farahi, J., Nacca, A., Monterosso, J. R., Mumford, J. A., et al. (2009). Striatal dopamine $\mathrm{d} 2 / \mathrm{d} 3$ receptor availability is reduced in methamphetamine dependence and is linked to impulsivity. Journal of Neuroscience, 29, 14734-14740.

Lee, N., Pennay, A., Harney, A., Kenny, P., \& Johns, L. (2007). Psychostimulant withdrawal: Naturnal history and options for treatment. Victoria, Australia: Department of Human Services.

London, E., Berman, S., Voytek, B., Simon, S., Mandelkern, M., Monterosso, J., Thompson, P., et al. (2005). Cerebral metabolic dysfunction and impaired vigilance in recently abstinent methamphetamine abusers. Biological Psychiatry, 58, 770-778.

Madras, B. K., Xie, Z., Lin, Z., Jassen, A., Panas, H., Lynch, L., Johnson, R., et al. (2006). Modafinil occupies dopamine and norepinephrine transporters in vivo and modulates the transporters and trace amine activity in vitro. Journal of Pharmacology and Experimental Therapeutics, 319, 561-569.

Marissen, M. A., Franken, I. H., Waters, A. J., Blanken, P., van den Brink, W., \& Hendriks, V. M. (2006). Attentional bias predicts heroin relapse following treatment. Addiction, 101, 1306-1312.

Mccann, U. D., Kuwabara, H., Kumar, A., Palermo, M., Abbey, R., Brasic, J., Ye, W., et al. (2007). Persistent cognitive and dopamine transporter deficits in abstinent methamphetamine users. Synapse, 62, 91-100.

McElhiney, M. C., Rabkin, J. G., Rabkin, R., \& Nunes, E. V. (2009). Provigil (modafinil) plus cognitive behavioral therapy for methamphetamine use in HIV + gay men: A pilot study. American Journal of Drug and Alcohol Abuse, 35, 34-37.

McGaugh, J., Mancino, M. J., Feldman, Z., Chopra, M. P., Gentry, W. B., Cargile, C., \& Oliveto, A. (2009). Open-label pilot study of modafinil for methamphetamine dependence. Journal of Clinical Psychopharmacology, 29, 488-491.

McGregor, C., Srisurapanont, M., Jittiwutikarn, J., Laobhripatr, S., Wongtan, T., \& White, J. M. (2005). The nature, time course and severity of methamphetamine withdrawal. Addiction, 100, $1320-1329$.

McGregor, C., Srisurapanont, M., Mitchell, A., Wickes, W., \& White, J. M. (2008). Symptoms and sleep patterns during inpatient treatment of methamphetamine withdrawal: A comparison of mirtazapine and modafinil with treatment as usual. Journal of Substance Abuse Treat, 35, 334-342.

McKetin, R., Kelly, E., \& McLaren, J. (2006). The relationship between crystalline methamphetamine use and methamphetamine dependence. Drug and Alcohol Dependence, 85, 198204.

Mcketin, R., McLaren, J., Kelly, E., Hall, W., \& Hickman, M. (2005). Estimating the number of regular and dependent methamphetamine users in Australia. Sydney: National Drug and Alcohol Research Centre.

McKetin, R., McLaren, J., Lubman, D. I., \& Hides, L. (2006). The prevalence of psychotic symptoms among methamphetamine users. Addiction, 101, 1473-1478.

McLaughlin, D. F., McKenna, H., \& Leslie, J. C. (2000). The perceptions and aspirations illicit drug users hold toward health care staff and the care they receive. Journal of Psychiatric and Mental Health Nursing, 7, 435-441.
Meredith, C., Jaffe, C., \& Ang-Lee, K. (2005). Implications of chronic methamphetamine use: A literature review. Harvard Review of Psychiatry, 13, 141-154.

Minzenberg, M. J., \& Carter, C. S. (2007). Modafinil: A review of neurochemical actions and effects on cognition. Neuropsychopharmacology, 33, 1-26.

Monterosso, J. R., Ainslie, G., Xu, J., Cordova, X., Domier, C. P., \& London, E. D. (2007). Frontoparietal cortical activity of methamphetamine-dependent and comparison subjects performing a delay discounting task. Human Brain Mapping, 28, 383393.

Monterosso, J. R., Aron, A. R., Cordova, X., Xu, J., \& London, E. D. (2005). Deficits in response inhibition associated with chronic methamphetamine abuse. Drug and Alcohol Dependence, 79, 273-277.

Morein-Zamir, S., Turner, D. C., \& Sahakian, B. J. (2007). A review of the effects of modafinil on cognition in schizophrenia. Schizophrenia Bulletin, 33, 1298-1306.

Nordahl, T. E., Salo, R., \& Leamon, M. (2003). Neuropsychological effects of chronic methamphetamine use on neurotransmitters and cognition: A review. Journal of Neuropsychiatry and Clinical Neurosciences, 15, 317-325.

Paulus, M., Tapert, S., \& Schuckit, M. (2005). Activation patterns of methamphetamine-dependent subjects during decision making predict relapse. Archives of General Psychiatry, 62, 761768.

Randall, D. C., Fleck, N. L., Shneerson, J. M., \& File, S. E. (2004). The cognitive-enhancing properties of modafinil are limited in non-sleep-deprived middle-aged volunteers. Pharmacology, Biochemistry and Behavior, 77, 547-555.

Salo, R., Nordahl, T., Possin, K., Leamon, M., \& Gibson, D. (2002). Preliminary evidence of reduced cognitive inhibition in methamphetamine-dependent individuals. Psychiatry Research, 111, 65-74.

Salo, R., Nordahl, T. E., Moore, C., Waters, C., Natsuaki, Y., Galloway, G. P., Kile, S., et al. (2005). A dissociation in attentional control: Evidence from methamphetamine dependence. Biological Psychiatry, 57, 310-313.

Salo, R., Nordahl, T. E., Possin, K., Leamon, M., Gibson, D. R., Galloway, G. P., Flynn, N. M., et al. (2002). Preliminary evidence of reduced cognitive inhibition in methamphetaminedependent individuals. Psychiatry Research, 111, 65-74.

Schoenmakers, T. M., Bruin, M. D., Lux, I. F., Goertz, A. G., Kerkhof, D. H. V., \& Wiers, R. W. (2010). Clinical effectiveness of attentional bias modification training in abstinent alcoholic patients. Drug and Alcohol Dependence, 109, 30-36.

Scott, J. C., Woods, S. P., Matt, G. E., Meyer, R. A., Heaton, R. K., Atkinson, J. H., \& Grant, I. (2007). Neurocognitive effects of methamphetamine: A critical review and meta-analysis. Neuropsychology Review, 17, 275-297.

Shearer, J., Darke, S., Rodgers, C., Slade, T., van Beek, I., Lewis, J., Brady, D., et al. (2009). A double-blind, placebo-controlled trial of modafinil (200 mg/day) for methamphetamine dependence. Addiction, 104, 224-233.

Shoptaw, S. J., Kao, U., Heinzerling, K., \& Ling, W. (2009). Treatment for amphetamine withdrawal. Cochrane Database System Review, CD003021.

Simon, S., Dacey, J., Glynn, S., Rawson, R., \& Ling, W. (2004). The effect of relapse on cognition in abstinent methamphetamine abusers. Journal of Substance Abuse Treatment, 27, $59-66$.

Simon, S. L., Dean, A. C., Cordova, X., Monterosso, J. R., \& London, E. D. (2010). Methamphetamine dependence and neu- 
ropsychological functioning: Evaluating change during early abstinence. Journal of Studies on Alcohol Drugs, 71, 335-344.

Simon, S. L., Domier, C. P., Sim, T., Richardson, K., Rawson, R. A., \& Ling, W. (2002). Cognitive performance of current methamphetamine and cocaine abusers. Journal of Addictive Diseases, 21, 61-74.

Streeter, C. C., Terhune, D. B., Whitfield, T. H., Gruber, S., Sarid-Segal, O., Silveri, M. M., Tzilos, G., et al. (2008). Performance on the Stroop predicts treatment compliance in cocaine-dependent individuals. Neuropsychopharmacology, 33, 827-836.

Thompson, P. M. (2004). Structural abnormalities in the brains of human subjects who use methamphetamine. Journal of Neuroscience, 24, 6028-6036.

Turner, D. C., Clark, L., Dowson, J., Robbins, T. W., \& Sahakian, B. J. (2004). Modafinil improves cognition and response inhibition in adult attention-deficit/hyperactivity disorder. Biological Psychiatry, 55, 1031-1040.

Turner, D. C., Clark, L., Pomarol-Clotet, E., McKenna, P., Robbins, T. W., \& Sahakian, B. J. (2004). Modafinil improves cognition and attentional set shifting in patients with chronic schizophrenia. Neuropsychopharmacology, 29, 1363-1373.

Turner, D. C., Robbins, T. W., Clark, L., Aron, A. R., Dowson, J., \& Sahakian, B. J. (2003). Cognitive enhancing effects of modafinil in healthy volunteers. Psychopharmacology (Berlin), 165, 260-269.
United Nations Office on Drugs \& Crime. (2007). 2007 world drug report. Vienna: Vienna International Centre.

Volkow, N. D., Chang, L., Wang, G. J., Fowler, J. S., Franceschi, D., Sedler, M., Gatley, S. J., et al. (2001). Loss of dopamine transporters in methamphetamine abusers recovers with protracted abstinence. Journal of Neuroscience, 21, 9414-9418.

Volkow, N. D., Chang, L., Wang, G. J., Fowler, J. S., LeonidoYee, M., Franceschi, D., Sedler, M. J., et al. (2001). Association of dopamine transporter reduction with psychomotor impairment in methamphetamine abusers. The American Journal of Psychiatry, 158, 377-382.

Volkow, N. D., Fowler, J. S., Logan, J., Alexoff, D., Zhu, W., Telang, F., Wang, G. J., et al. (2009). Effects of modafinil on dopamine and dopamine transporters in the male human brain: Clinical implications. Journal of the American Medical Association, 301, 1148-1154.

Waters, A. J., Shiffman, S., Sayette, M. A., Paty, J. A., Gwaltney, C. J., \& Balabanis, M. H. (2003). Attentional bias predicts outcome in smoking cessation. Health Psychology, 22, 378 387.

Westcott, K. J. (2005). Modafinil, sleep deprivation, and cognitive function in military and medical settings. Military Medicine, 170, 333-335.

Received June 27, 2010

Revision received October 6, 2010 Accepted October 8, 2010

\section{Online First Publication}

APA-published journal articles are now available Online First in the PsycARTICLES database. Electronic versions of journal articles will be accessible prior to the print publication, expediting access to the latest peer-reviewed research.

All PsycARTICLES institutional customers, individual APA PsycNET ${ }^{\circledR}$ database package subscribers, and individual journal subscribers may now search these records as an added benefit. Online First Publication (OFP) records can be released within as little as 30 days of acceptance and transfer into production, and are marked to indicate the posting status, allowing researchers to quickly and easily discover the latest literature. OFP articles will be the version of record; the articles have gone through the full production cycle except for assignment to an issue and pagination. After a journal issue's print publication, OFP records will be replaced with the final published article to reflect the final status and bibliographic information. 